\title{
Electrochemical Corrosion Study of Zircaloy-4 in a LiOH Solution at High Temperature and Pressure
}

\author{
Zhuo Wang ${ }^{1,2}$, Heping $\mathrm{Li}^{1 *}$, Liping Xu ${ }^{1}$, Qingyou Liu ${ }^{1}$, Lei Zha ${ }^{1,2}$, Sen Lin ${ }^{1}$ \\ ${ }^{1}$ Key Laboratory of High Temperature and High Pressure Study of the Earth's Interior, Institute of \\ Geochemistry, Chinese Academy of Sciences, Guiyang, China \\ ${ }^{2}$ University of Chinese Academy of Sciences, Beijing, 100039, China \\ *E-mail: liheping@vip.gyig.ac.cn
}

doi: $10.20964 / 2018.12 .20$

Received: 27 July 2018 / Accepted: 21 September 2018 / Published: 5 November 2018

\begin{abstract}
The electrochemical corrosion of Zircaloy- 4 in simulated pressurized water reactor coolant at $350^{\circ} \mathrm{C}$ was studied via in situ potentiodynamic polarization and electrochemical impedance spectroscopy (EIS) measurements. The potentiodynamic polarization results indicate that the corrosion potential of Zircaloy-4 decreases and its corrosion current density increases when the concentration of $\mathrm{LiOH}$ increases, showing that Zircaloy-4 corrodes more easily and faster in higher concentrations of LiOH. In addition, the EIS data fits the double layer oxide model, which consists of a porous non-protective outer layer and a dense protective inner barrier layer. The EIS data suggest that the corrosion resistance of the two oxide layers both decrease with the increasing $\mathrm{LiOH}$ concentration. Our study shows that increasing the $\mathrm{LiOH}$ concentration benefits the electrochemical corrosion of Zircaloy-4 in hightemperature and high-pressure aqueous solutions.
\end{abstract}

Keywords: Zircaloy-4; EIS; polarization; corrosion; oxidation; Modeling and Simulation

\section{FULL TEXT}

(C) 2018 The Authors. Published by ESG (www.electrochemsci.org). This article is an open access article distributed under the terms and conditions of the Creative Commons Attribution license (http://creativecommons.org/licenses/by/4.0/). 